\title{
LUT
}

University

Reflective practice as a determinant of performance outcomes in services

Saunila Minna, Ukko Juhani

This is a Post-print

version of a publication

published by Emerald Group Publishing

in International Journal of Quality and Service Sciences

DOI: $10.1108 /$ IJQSS-02-2015-0015

Copyright of the original publication: @ 2015, Emerald Group Publishing

Please cite the publication as follows:

Saunila, M., Ukko, J. (2015). Reflective practice as a determinant of performance outcomes in services. International Journal of Quality and Service Sciences, vol. 7, issue 4. pp. 392-403. DOI:

10.1108/IJQSS-02-2015-0015

This is a parallel published version of an original publication.

This version can differ from the original published article. 


\section{REFLECTIVE PRACTICE AS A DETERMINANT OF PERFORMANCE OUTCOMES IN SERVICES}

\section{Structured Abstract:}

Purpose - This research examines the outcomes of reflective practices in services. The paper contributes to the current understanding of the relationship between reflective practice and outcomes by presenting a description of the internal (i.e., what kind of reflection is required to attain the desired outcomes) and external (i.e., under what kind of circumstances does reflection result in the desired outcomes) factors of reflective practices.

Design/methodology/approach - The results of this investigation are based on a mixed method research approach that utilises both quantitative and qualitative data collection methods.

Findings - According to the results, reflective practices are indeed connected to outcomes. Reflective practices foster better outcomes when they are more explicit and targeted through different organisational levels. The role of performance management and measurement is important in connecting the reflective practices with performance. Performance management must be considered as a communication and social system that allows the employees to discuss the learning and development process as a part of the results.

Practical implications - As a practical contribution, the results of the research may help professionals begin to understand that leveraging reflective practices may aid an organisation in achieving its desired outcomes.

Originality/value - Hitherto, studies that discuss the interphase of reflective practices and outcomes have mainly been theoretical considerations or surveys that lack an in-depth understanding of how the different methods operate in a real life context. When focusing on the previous research, it is clear that in-depth empirical studies are needed to achieve a deeper understanding of the mechanisms and arrangements that connect reflective practice and outcomes. This research addresses this research gap by examining the outcomes of reflective practices in services.

Keywords: Reflective practice, service, outcome, performance, performance management, performance measurement

Publisher: Emerald Group Publishing Limited 
Saunila, M., \& Ukko, J. (2015). Reflective practice as a determinant of performance outcomes in services. International Journal of Quality and Service Sciences, 7(4), 392-403.

\section{Introduction}

It has been suggested that innovation is one of the most important issues driving organisational performance. When it comes to services, the traditional forms of developing innovation do not fulfil the needs of a rapidly changing environment. New ways of developing organisational innovation are thus needed. Reflective practices, wherein individuals learn from their own professional experiences, may be the most important source of professional development and improvement (Nakamura and Yorks, 2011), as well as innovation and other outcomes. Indeed, earlier literature reported some positive effects of reflective practices (e.g., Page and Meerabeau, 2000). There are some examples in the current literature suggesting that team reflection is a driver of both team innovation (Somech, 2006) and product innovation (Lee, 2008). According to Somech (2006), the process of team reflection serves as a vehicle through which the interaction of a participative leadership style and functional heterogeneity enhances team innovation. Numerous similar factors are behind reflective practice and innovation development. These include such things as individual skills and capabilities, collective culture and structural aspects. Clouder (2000) argued that if reflective practice stops at the individual, instead of promoting change, it would be limited in scope and serve only to maintain the status quo. Therefore, reflective practice can also be realised in group and organisational levels (Hildén and Tikkamäki, 2013). The literature on the strategies to foster reflective practices is still early in development and there is a lack of studies addressing the outcomes of reflective practices (Mann et al., 2009), namely organisational level innovation and outcomes.

It is clear from an examination of the previous research that in-depth empirical studies are needed to achieve a deeper understanding of the mechanisms and arrangements that connect reflective practice and outcomes. The studies that discuss the interphase of reflective practices and outcomes have mainly been theoretical considerations or surveys that lack an in-depth understanding of how the different methods operate in a real life context. This study aims to address this research gap by examining the outcomes of reflective practices in services. The paper argues that reflective practices are a means of improving outcomes in services. To achieve these goals, the paper contains a description of the internal (i.e., what kind of reflection is required to attain desired outcomes) and external (i.e., under what type of circumstances does reflection result in the desired outcomes) factors of reflective practices.

This paper is structured as follows. First, a review of the literature that focuses on reflective practice in services is conducted. In the literature review, the relevant research considering the aims of this paper is examined to formulate the research gap. The next section explains the research methodology used in this study. In section 4, the results are presented in terms of what kind of reflection and under what kind of circumstances reflection is required to attain the desired outcomes. The paper concludes with a discussion of the implications of the work and recommendations for further research. 
Saunila, M., \& Ukko, J. (2015). Reflective practice as a determinant of performance outcomes in services. International Journal of Quality and Service Sciences, 7(4), 392-403.

\section{Literature review}

\subsection{Reflective practice}

Continuous professional development should not be merely attending courses and gaining qualifications, but an integration of learning and work, and learning from wider experiences, both on and off the job. Today, by utilising human resources to cope with and successfully manage change, developing organisations are seen as using a combination of structured and unstructured learning and performance-based activities that develop individual and organisational capacity (Simmonds and Pedersen, 2006). Organisational learning theories present learning as a method of solving problems by examining the appropriateness of current learning behaviours and questioning the assumptions that underlie the existing methods of working (Argyris and Schön, 1978). These theories have highlighted the importance of the concept of reflection and reflective practice. Traditional approaches may ignore how process factors such as flexibility, informality, feedback and autonomy might influence knowledge creation (Nonaka, 1994). However, unless the learner reflects on the experience in terms of his or her existing understanding and assumptions, experience does not automatically lead to learning (Kolb, 1984). Refection is required to change routine thinking and behaviour. In this paper, reflective practice is seen a means of improving the meta skills that can be learned only through experience.

The field of learning from experience illuminates the importance of reflection (Nakamura and Yorks, 2011). It has been suggested that reflection can be an important tool of developing human resources when individuals learn from their own and each other's professional experiences, rather than from formal training. Boud defines reflection as 'a generic term for those intellectual and affective activities in which individuals engage to explore their experiences in order to lead to a new understanding and appreciation' (in Mann et al., 2009). Reflection involves thinking about past or ongoing events, situations or actions with the intention of making sense of them, potentially with a view towards informing future choices, decisions or actions (Reynolds, 2011). Reflection thus fulfils several functions, including helping to make sense of complex situations and enabling learning from earlier experience (Mann et al., 2009).

The term 'reflective practice' has been widely used in the discussion of reflection in organisational development. According to Schön (1983), reflective practice is 'the capacity to reflect on action so as to engage in a process of continuous learning'. Hildén and Tikkamäki (2013) consider reflective practice as the actual ways in which reflection is manifested through individual and collective action within the organisational realm. Reflective practices are connected to learning processes, as people interact and effectively share ideas and opinions as well as discussing possible solutions (Høyrup, 2004). In the presence of group work, the ability to reflect seems to be amenable to development over time and with practice. Discussing 
Saunila, M., \& Ukko, J. (2015). Reflective practice as a determinant of performance outcomes in services. International Journal of Quality and Service Sciences, 7(4), 392-403.

challenging situations or problems with supervisors, mentors, colleagues and others with greater experience appears to be important for reflection (Mann et al., 2009; Nakamura and Yorks, 2011). Support for planning and reflective practice is indeed essential. This can come true through the freedom and possibility to reflect, make plans, keep meetings and obtain feedback on actions and plans (Høyrup, 2004). The literature on creativity and learning indicate that organisational conditions can facilitate learning and therefore reflection. It has been stated that one condition, namely cultural access, can have positive effects on individual well-being (Grossi et al., 2011). This type of informal off the job training is important to learning and it can have an important role in the implications of reflection.

According to Hildén and Tikkamäki (2013), to understand the reflection process holistically, the processes need to be connected explicitly at the individual, group and organisational levels. All three organisational levels are simultaneously present and must be acknowledged in any reflective practice. One way to do this is through performance management systems, which can be regarded as communication and social systems (Bititci et al., 2012), and thus supporting reflection.

\subsection{Consequences of reflective practice}

Reflection enhances a learner's awareness of his or her abilities and it promotes independent learning. When learners reflect on their own performance, it promotes metacognitive awareness of performance and the processes behind it; this awareness is regarded as essential for autonomous learning (cf. Chen, 2008; Little, 2007). Reflection may also be a useful tool to empower people to initiate change without having that change imposed on them (Page and Meerabeau, 2000).

It has been widely acknowledged that, at its best, reflection can generate a variety of outcomes, such as with job satisfaction (Page and Meerabeau, 2000) and innovation (Somech, 2006; Lee, 2008). Some examples in the current literature suggest that team reflection is a driver of both team (Somech, 2006) and product innovation (Lee, 2008). According to Somech (2006), the process of team reflection serves as a vehicle through which the interaction of participative leadership style and functional heterogeneity enhances team innovation. Reflective project leadership, meaning questioning one's own leadership behaviour, can be a means for a project leader to promote innovativeness (Ollila, 2000).

One criticism of reflective practice is its association with the production of individual knowledge (Clouder, 2000). Hitherto, the research investigating the consequences of reflective practice has concentrated on the consequences of individual or group reflection. However, organisational level reflection and its consequences have not received attention. This research adopts a more holistic perspective of reflective practice. Indeed, reflective practice can be realised at the individual, group and organisational levels. Furthermore, Ukko et al. (2014) state 
Saunila, M., \& Ukko, J. (2015). Reflective practice as a determinant of performance outcomes in services. International Journal of Quality and Service Sciences, 7(4), 392-403.

that when reflective practices become more explicit and are targeted through different organisational levels, they foster better organisational outcomes.

\section{$3 \quad$ Research methodology}

\subsection{Empirical research setting}

This study is exploratory and utilises a mixed method research approach (Creswell, 2003; Teddlie and Tashakkori, 2009). The studied organisation is located in southern Finland and operates in the service sector in the fields of construction, decorating and gardening. The case organisation consists of two units with a total of 70 workers. Although the organisation compares very favourably to its competitors in terms of financial measures, the economic situation has forced it to find new ways to develop its operations. Cutting costs is not an answer to success. Therefore, an operational change was implemented. Of necessity, sales personnel must spend significantly more time directly with customers, which requires an identity change as well as new competencies and attitude.

Although the organisation utilised traditional classroom training in the past, due to highly competitive markets and an intensified financial situation, reflective practices, where individuals learn both from their own and from each other's professional experiences, were seen as a potentially important source of professional development and improvement. While the store was established in 2007 , and has therefore had the potential for the development of reflective practice, it has hitherto failed to scrutinise its potential to gain a competitive advantage. A reflective dialogue was organised in the development project. The aim was to observe whether and how it reaches the level of open and influential interaction. In addition, potential tools were identified to share the individual output of each participant's thinking, thus producing more creative and multifaceted ideas. The development project was conducted in the organisation during the years 2012-2014, after which the outcomes of the reflective practice were examined. The researchers were involved in the reflective practice development project, which increased their pre-understanding of the case context. This was regarded as crucial to examining the outcomes of reflective practice.

\subsection{Data collection}

Both quantitative and qualitative methods of data collection were utilised in this investigation. First, a survey was conducted to trace the relationship between reflective practice and outcomes. Second, interviews were conducted to clarify how the mechanisms between reflective practice and outcomes operate.

\subsubsection{Quantitative methods}


Saunila, M., \& Ukko, J. (2015). Reflective practice as a determinant of performance outcomes in services. International Journal of Quality and Service Sciences, 7(4), 392-403.

The survey included 15 items to measure reflective practice (adopted from Hildén and Tikkamäki, 2013). The survey of reflective practice is presented in Table 1. A Likert-type scale ranging from strongly disagree to strongly agree was adopted. A neutral response, 'neither disagree nor agree', was adopted to reduce uninformed responses.

Table 1. The survey for reflective practice

\begin{tabular}{|c|c|c|c|}
\hline Level of reflective practice & Items & Description & Alpha value \\
\hline $\begin{array}{l}\text { Reflective practice on } \\
\text { individual level }\end{array}$ & 5 & $\begin{array}{l}\text { Within intuiting and interpreting } \\
\text { processes }\end{array}$ & 0.779 \\
\hline $\begin{array}{l}\text { Reflective practice on } \\
\text { group level }\end{array}$ & 5 & $\begin{array}{l}\text { Within interpreting and integrating } \\
\text { processes }\end{array}$ & 0.747 \\
\hline $\begin{array}{l}\text { Reflective practice on } \\
\text { organisational level }\end{array}$ & 5 & $\begin{array}{l}\text { Within integrating and institutionalising } \\
\text { processes }\end{array}$ & 0.867 \\
\hline
\end{tabular}

The survey included two items to measure job satisfaction and two items to measure service performance (to reflect the people-related outcomes of the reflective practice). The job satisfaction items were adopted from Valentine et al. (2011) and the service performance items were adopted from Chuang and Liao (2010). For each of the four outcome items, the respondents were asked to indicate their opinion on a scale ranging from 1 (weak) to 4 (excellent). The surveys were sent to all employees of the organisation. This process resulted in a total of 49 responses, accounting for a 70 per cent final response rate. Because the aim was to determine the connection between variables, the survey data was evaluated using a linear regression analysis.

\subsubsection{Qualitative methods}

In the second part of the study, two group interviews were conducted in the case organisation. Representatives of all levels of the organisation were interviewed to achieve an inclusive perspective of the outcomes of reflective practice. The interviewees included two top managers and four sales managers from different units and departments. The interviews focused on the same three levels of reflective practice that were utilised in the survey tool. As an example, the themes of the interviews included the following three issues: 1) the prerequisites of the reflective practices in work, 2) the factors related to reflective practices that have led to good financial performance and 3) the mechanisms between reflective practices and outcomes. Although the interview questions were determined in advance, the discussions were informal and were facilitated using supporting questions and comments by the researchers. This enabled an in-depth understanding of the phenomenon under investigation. To clarify under what kind of circumstances reflection results in desired outcomes, content analysis was carried out in the studied issues. The core questions of the semi-structured interviews are presented in the Appendix. 
Saunila, M., \& Ukko, J. (2015). Reflective practice as a determinant of performance outcomes in services. International Journal of Quality and Service Sciences, 7(4), 392-403.

\section{Results}

\subsection{What kind of reflection is required to attain the desired outcomes?}

Table 2 presents the intercorrelations of the variables used in this study. All three levels of reflective practice were found to have significant and positive correlations with job satisfaction. Correlations were not significant with the levels of reflective practice and service performance.

Table 2. Intercorrelations of the variables

\begin{tabular}{llll}
\hline & Individual & Group & Organisation \\
\hline Job satisfaction & $.391^{* *}$ & $.486^{* * *}$ & $.646^{* * *}$ \\
Service performance & -.203 & -.077 & .131 \\
\hline
\end{tabular}

Sign. ${ }^{* *} \leq 0.001, * * 0.001<\mathrm{p} \leq 0.01$

Based on the analyses presented in Table 3, all three levels of reflective practice are connected both significantly and positively to job satisfaction. The regression model studying the relationship between reflective practice on individual level and job satisfaction is significant ( $F=4.854)$. The adjusted $\mathrm{R}^{2}$ is 0.106 , meaning that 10.6 per cent of the variance in the dependent variable (job satisfaction) can be explained by individual level reflective practice. The regression model of the connection between reflective practice on group level and job satisfaction is significant $(\mathrm{F}=10.134)$, while 19.1 per cent of the variance in job satisfaction can be explained by group level reflective practice. The model of reflective practice on organisational level is also significant $(\mathrm{F}=32.214)$, explaining 44.6 per cent of the variance in job satisfaction. The results indicate that reflective practice in all three levels tends to be positively related to job satisfaction, which is consistent with the predictions. Nonetheless, the models investigating the connection between the three levels of reflective practice and service performance were not significant. Therefore, it can be concluded from the regression results that all three levels of reflective practice are connected to people related outcomes. However, this applies only to job satisfaction, not service performance.

Table 3. Results of the regression analysis of the variables

\begin{tabular}{lllllll}
\hline $\begin{array}{l}\text { Independent } \\
\text { variable }\end{array}$ & $\begin{array}{l}\text { Reflective } \\
\text { practice in }\end{array}$ & $\begin{array}{l}\text { Different } \\
\text { levels }\end{array}$ & & & & \\
\cline { 2 - 7 } & Individual & Group & Organisation & Individual & Group & Organisation \\
\cline { 2 - 7 } & Beta & Beta & Beta & Beta & Beta & Beta \\
\hline $\begin{array}{l}\text { Dependent } \\
\text { variable }\end{array}$ & & & & & & \\
$\begin{array}{l}\text { Job satisfaction } \\
\begin{array}{l}\text { Service } \\
\text { performance }\end{array}\end{array}$ & $.325^{*}$ & $.437^{* *}$ & $.668^{* * *}$ & & & \\
\end{tabular}


Saunila, M., \& Ukko, J. (2015). Reflective practice as a determinant of performance outcomes in services. International Journal of Quality and Service Sciences, 7(4), 392-403.

\begin{tabular}{lllllll}
$\mathrm{F}$ & $4.854^{*}$ & $10.134^{* *}$ & $32.214^{* * *}$ & 1.360 & .108 & 2.362 \\
$\mathrm{R}$ & .325 & .437 & .668 & .177 & .049 & .221 \\
$\mathrm{R}^{2}$ & .106 & .191 & .446 & .031 & .002 & .049 \\
\hline
\end{tabular}

Sign. ${ }^{* * *} \leq 0.001,{ }^{* *} 0.001<\mathrm{p} \leq 0.01, * 0.01<\mathrm{p} \leq 0.05$

\subsection{Under what kind of circumstances does reflection result in the desired outcomes?}

Based on the interviews, the main prerequisites for reflection are the right capabilities and resources for working. This means the understanding of a job description, the appropriate skills for a job, organisational support, up-to-date tools and enough time for the tasks. This enables proper focus, time and energy for reflection and development in an individual level. This encourages breaking the organisational boundaries and discussing the critical issues, simultaneously enabling change in the old routines. Nonetheless, it is essential to understand that these prerequisites need to be acknowledged both in the group and organisational levels associated with rewarding the consultative culture.

The results of the interviews strengthened the notion that reflective practice at an organisational level is crucial for attaining outcomes. Multiple issues were disclosed to foster a connection between reflective practices and the desired outcomes.

- The development subjects/themes that the reflective practices are intended to influence need to be limited to a few key themes and the connection to performance needs to be both justified and discussed.

- A variety of reflective practices can be utilised to facilitate the selected themes.

- The reflection needs to be target-oriented at the individual, group and organisational levels.

- Different organisational levels need their own measures and targets for the selected themes on which the reflective practices are believed to have an effect.

- The measures and targets of different organisational levels need to be in line with each other.

- Work satisfaction, motivation and commitment are important features for the reflective actions.

- To enable reflectiveness as well as both individual and organisational learning, the performance management systems have to be considered as communication and social systems.

Although a number of organisational level measures need to be achieved in the case organisation, the common perception of the interviewees was that the reflective practices could only be linked to a couple of themes. This means that the utilisation of reflective practices 
Saunila, M., \& Ukko, J. (2015). Reflective practice as a determinant of performance outcomes in services. International Journal of Quality and Service Sciences, 7(4), 392-403.

needs to be controlled to a certain point and a clear message sent to the employees as to what the contemporary development targets are. Otherwise, the employees have too many issues on which they need to focus, which may lead to unfinished development actions. The managers thus need to filter the right development targets and justify their connection to performance. In the case organisation, the key development targets were outlined as follows: 1) multi-skills (technical \& product), 2) active sales approach and willingness to serve, 3) coaching skills and 4) system skills. These development targets were directed towards achieving superior customer experience results in service. These development targets were measured in all three levels of reflective practice: individual, group and organisational. The connection of these targets to financial performance was highlighted in all possible situations that allow reflection:

- The managers took a contact to all of the employees every day

$\circ$ Managing individuals

- The managers had conversations with all of the employees (presence, meeting)

- Increasing the meaning of work by the interest of the managers

- The managers gave the employees problems to solve (effectiveness)

- Activating employees

- Regular small group meetings

$\circ$ Increasing the openness and facilitating the transmission of tacit knowledge

In all of the above situations, the development targets and/or measurement information was discussed and highlighted, both formally and informally. These situations were perceived as good places for reflection and learning, and considered as reflective practices.

As an example of reflective practices, the interviews resulted in factors beyond the good financial performance in the case organisation. In comparison to other stores, the studied units made their own targets and decisions in addition to the efficiency targets that were launched by the chain control. By allowing them to ideate the actions towards the desired targets, these decisions were made together with the employees. This allowed the possibility of avoiding the redundancies and reorganising the tasks, which was perceived as a better work atmosphere and a motivational aspect that strengthened the commitment of the employees. This in turn promoted the thinking that the work is something that needs to be developed, which is realised as excellent service, a service culture and positive service experiences (customer satisfaction feedback). The sense of being excellent as sellers was strengthened through the reflective practices.

\subsection{Summary}

Table 4 below provides a summary of the results of the quantitative and qualitative parts of the research. 
Saunila, M., \& Ukko, J. (2015). Reflective practice as a determinant of performance outcomes in services. International Journal of Quality and Service Sciences, 7(4), 392-403.

Table 4. Summary of the results

\begin{tabular}{l|l|l}
\hline \multicolumn{2}{c}{ Outcomes of reflective practice } \\
\cline { 2 - 3 } $\begin{array}{l}\text { Reflective practice } \\
\text { on individual level }\end{array}$ & + & Under what kind of circumstances \\
\hline $\begin{array}{l}\text { Reflective practice } \\
\text { on group level }\end{array}$ & ++ & $\begin{array}{l}\text { Clear job description } \\
\text { Appropriate skills for a job } \\
\text { Organisational support } \\
\text { Up-to-date tools } \\
\text { Enough time for the tasks }\end{array}$ \\
\hline $\begin{array}{l}\text { Reflective practice } \\
\text { on organisational } \\
\text { level }\end{array}$ & +++ & $\begin{array}{l}\text { Regular small group meetings } \\
\text { Organisational support } \\
\text { Up-to-date tools } \\
\text { Enough time for the tasks }\end{array}$ \\
\hline & & $\begin{array}{l}\text { Target-oriented } \\
\text { Clear and limited key themes } \\
\text { Connection to performance justified and discussed } \\
\text { Assisted by performance measurement (facilitating reflective } \\
\text { practice as a communication and social system) }\end{array}$ \\
\hline
\end{tabular}

\section{Discussion}

Reflection is a multifaceted phenomenon that can be examined in different organizational levels. Hitherto, most studies have focused on the exploitation of reflective practices at an individual level that enables learning from earlier experience (cf. Mann et al., 2009). Some results concerning the outcomes of team reflection have also been reported (cf. Somech, 2006; Lee, 2008). In this paper, the relationship between reflective practices and service performance was studied in the individual, group and organisational levels. While the results did not indicate significant relations in any of the studied levels, they are somewhat contradictory to those of Somech (2006) and Lee (2008), which indicate some innovation-related outcomes. Although a significant relationship was found between the reflective practices and job satisfaction, thus supporting the study of Page and Meerabeau (2000), it seems that reflective practice is still connected to people related outcomes. The branch of the organisation and the job description of the respondents could explain the non-significant relationship between the reflective practices and the service performance. The respondents were sales personnel in a hardware store, which does not allow major changes to the job descriptions, compared, for example, to more knowledge-intensive jobs such as those of consultants and other experts.

The interviews showed that the reflective practices do not work per se. However, a number of issues can be presented that facilitate the exploitation of reflection towards the desired outcomes. The reflective practices need to be limited to a few key themes and the connection to the performance needs to be justified and discussed. Different organisational levels need their own measures and targets for the selected themes on which the reflective practices are believed to have an effect. These features are also common to the general literature regarding the performance measurement of an organisation (Ukko et al., 2007; 2008). The other features 
Saunila, M., \& Ukko, J. (2015). Reflective practice as a determinant of performance outcomes in services. International Journal of Quality and Service Sciences, 7(4), 392-403.

that enable performance-based reflection are work satisfaction, motivation and commitment. The results strongly support the results of Bititci et al. (2012), highlighting that performance management systems have to be considered as both a communication and a social system. This enables reflectiveness as well as both individual and organisational learning. As a whole, the study supports the statement of Simmonds and Pedersen (2006) in maintaining that human resources should be considered a combination of structured and unstructured learning and performance-based activities that develop the individual and organisational capacity to cope with and successfully manage change.

\section{Conclusions}

This paper contains a description of the internal (i.e., what kind of reflection is required to attain desired outcomes) and external (i.e., under what kind of circumstances does reflection result in desired outcomes) factors of reflective practices. This investigation contributes to the current research by clarifying the connection between reflective practice and outcomes. According to the results, reflective practices are somewhat connected to outcomes. Reflective practices foster better outcomes when they are more explicit and targeted through different organisational levels. The role of performance management and measurement is important in connecting the reflective practices with performance. Measures that enable comparison and a reflection of the results, and simultaneously show the direction of the development are needed in all organisational levels. Nonetheless, performance management must be considered as a communication and social system that allows employees to discuss the learning and development process as a part of the results. As a practical contribution, the results of the research may help professionals begin to understand that leveraging reflective practices may aid an organisation in achieving its desired outcomes.

The results of this paper are based on a case study of one company, which limits the generalisability of the findings. Therefore, an assessment of its robustness is required and its adequacy needs to be validated. Although the results supported many of the propositions in the prior literature, they also generated a number of open questions for further research. First, it is not clear whether, and to what extent, reflective practice affects financial outcomes (e.g., profitability), competitive performance (e.g., the rate of customer loyalty and customer satisfaction), social performance (e.g., turnover and stakeholder satisfaction) and performance in innovative processes (e.g., services launched on the market). These should be a subject of future studies. Second, it is worth examining in more detail what types of impacts result when utilising reflective practice in other sectors. Third, it seems that the consequences of reflective practice are dependent on many factors, and it is thus important to study how reflective practice should be organised in different business areas and with different types of reflective processes. Further qualitative research should enable the ability to identify additional prerequisites that facilitate reflection and a better understanding of the links between reflection and performance 
Saunila, M., \& Ukko, J. (2015). Reflective practice as a determinant of performance outcomes in services. International Journal of Quality and Service Sciences, 7(4), 392-403.

outcomes. Additional quantitative research should subsequently validate the above aspects with larger samples.

\section{References}

Argyris, C.; Schön, D.A. (1978): Organizational Learning: A Theory of Action Perspective. Addison-Wesley: Reading, MA, USA.

Bititci, U.S.; Garengo, P.; Dörfler, V.; Nudurupati, S. (2012): Performance measurement: challenges for tomorrow. International Journal of Management Reviews 14, pp. 305-327.

Chen, Y.-M. (2008): Learning to self-assess oral performance in English: A longitudinal case study. Language Teaching Research 2, pp. 235-262.

Chuang, C-H.; Liao, H. (2010): Strategic human resource management in service context: taking care of business by taking care of employees and customers. Personnel psychology 63, pp. 153-196.

Clouder, L. (2000): Reflective Practice: Realising its potential. Physiotherapy 86, pp. 517-522.

Creswell, J.W. (2003): Research Design Qualitative, Quantitative and Mixed Methods Approaches. 2nd ed. Sage Publications: Thousand Oaks, California.

Grossi, E.; Sacco, P.L.; Blessi, G.T.; Cerutti, R. (2011): The Impact of Culture on the Individual Subjective Well-Being of the Italian Population: An Exploratory Study. Applied Research in Quality of Life 6, pp. 387-410.

Hildén, S.; Tikkamäki, K. (2013): Reflective Practice as a Fuel for Organizational Learning. Administrative Sciences 3, pp. 76-95.

Høyrup, S. (2004): Reflection as a core process in organisational learning. Journal of Workplace Learning 16, pp. 442-454.

Kolb, D.A. (1984): Experiential Learning: Experience as a Source of Learning and Development. Prentice-Hall: Englewood Cliffs, NJ, USA.

Lee, L.T-S. (2008): The effects of team reflexivity and innovativeness on new product development performance. Industrial Management \& Data Systems 108, pp. 548-569. 
Saunila, M., \& Ukko, J. (2015). Reflective practice as a determinant of performance outcomes in services. International Journal of Quality and Service Sciences, 7(4), 392-403.

Little, D. (2007): Knowledge about language and learner autonomy. In Cenoz, J.: Hornberger, N.H. (Eds.): Encylopedia of language and education. Knowledge about language (pp. 247260). Berlin: Springer Verlag.

Mann, K.; Gordon, J.; MacLeod, A. (2009): Reflection and reflective practice in health professions education: a systematic review. Advances in Health Sciences Education 14, pp. 595-621.

Nakamura, Y.T.; Yorks, L. (2011): The Role of Reflective Practices in Building Social Capital in Organizations From an HRD Perspective. Human Resource Development Review 10, pp. 222-245.

Nonaka, I. (1994): A Dynamic Theory of Organizational Knowledge Creation. Organization Science 5, pp. 14-37.

Ollila, S. (2000): Creativity and Innovativeness through Reflective Project Leadership. Creativity and Innovation Management 9, pp. 195-200.

Page, S.; Meerabeau, L. (2000): Achieving change through reflective practice: closing the loop. Nurse Education Today 20, pp. 365-372.

Reynolds, M. (2011): Reflective practice: origins and interpretations. Action Learning: Research and Practice 8, pp. 5-13.

Schön, D. (1983): The Reflective Practitioner. How professionals think in action. London: Temple Smith.

Simmonds, D.; Pedersen, C. (2006): HRD: the shapes and things to come. Journal of Workplace Learning 18, pp. 122-135

Somech, A. (2006): The Effects of Leadership Style and Team Process on Performance and Innovation in Functionally Heterogeneous Teams. Journal of Management 32, pp. 132-157.

Teddlie, C.; Tashakkori, A. (2009): Foundations of Mixed Methods Research: Integrating Quantitative and Qualitative Approaches in the Social and Behavioral Sciences. Sage Publications: Thousand Oakes, California.

Valentine, S.; Godkin, L.; Fleischman, G.M.; Kidwell, R. (2011): Corporate Ethical Values, Group Creativity, Job Satisfaction and Turnover Intention: The Impact of Work Context on Work Response. Journal of Business Ethics 98, pp. 353-372. 
Saunila, M., \& Ukko, J. (2015). Reflective practice as a determinant of performance outcomes in services. International Journal of Quality and Service Sciences, 7(4), 392-403.

Ukko, J.; Tenhunen, J.; Rantanen, H. (2007): Performance measurement impacts on management and leadership - perspectives of management and employees. International Journal of Production Economics 110, pp. 39-51.

Ukko, J.; Tenhunen, J.; Rantanen, H. (2008): The impacts of performance measurement on the quality of working life. International Journal of Business Performance Management 10, pp. 8698.

Ukko, J.; Hilden, S.; Saunila, M.; Rämö, J.; Tikkamäki, K.; Vauranoja, S; Pekkola, S. (2014); Performance-Driven HRD: Innovativeness and Performance through Reflective Practice. Working Paper.

APPENDIX: Core questions of the semi-structured interviews

Q1: What kind of effects have you noticed as a result of development actions in everyday work - in your behalf or more broadly in your company?

Q2: What do you think the reflectivity at work requires in terms of:
a) Individual: attitude, skills
b) Group: social competence
c) Organisation: policies and management

Q3: What kind of obstacles of reflectivity do you recognize in terms of:
d) Individual: attitude, skills
e) Group: social competence
f) Organisation: policies and management

Q4: If your company learned to act in a distinctly more reflective way - what would happen (reflection opportunities/risks)? 